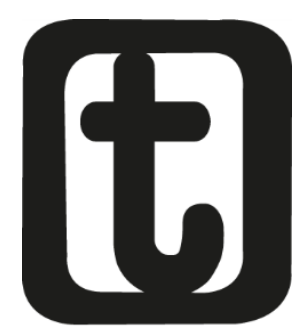

\title{
CONTROLE SOCIAL E REPRODUÇÃO CAPITALISTA: POLÊMICAS E ESTRATÉGIAS CONTEMPORÂNEAS
}

Control and capitalist reproduction: controversy and contemporary strategies

\section{Reivan Marinho de Souza'}

\section{RESUMO}

Debate alguns elementos sobre a temática controle social referenciada na concepção marxiana. Aborda teoricamente as bases do controle na sociedade capitalista, a relação entre controle social e a esfera da política e controle social e Serviço Social. Indaga sobre a possibilidade, nessa sociedade, do capital manter o controle da base material (produção social) para garantir a acumulação, e o trabalho construir formas de controle (estratégias sociais) para enfrentar as desigualdades sociais e promover a reversão do desenvolvimento histórico do capitalismo a favor de seus interesses. Argumenta que essa articulação é problemática devido às determinações do capital e à ocorrência das crises cíclicas e da crise estrutural que agrava e complexifica as conseqüências sociais da reprodução material e social do trabalho no mundo contemporâneo. Problematiza algumas estratégias históricas de enfrentamento do trabalho sobre as determinações

\footnotetext{
1 Doutora em Serviço Social. Professora do Programa de Pós-graduação (Mestrado) e do Curso de Graduação da Faculdade de Serviço Social da Universidade Federal de Alagoas (UFAL). E-mail: <reivansouza@yahoo.com.br>.
}

Temporalis, Brasilia (DF), ano 10, n.20, p.49-76, jul./dez. 2010. 


\section{temporalis}

SOUZA, R. M. de. POLÊMICAS E ESTRATÉGIAS CONTEMPORÂNEAS

estruturais do controle capitalista, discutindo os limites dessa relação entre a esfera da economia e a da política.

\section{PALAVRAS-CHAVE}

Controle social e Capitalismo. Controle social e Serviço Social. Política social e Controle social.

\section{ABSTRACT}

We argue about some topics related to the social control home which is referenced in the Marxian conception. This article discusses, theoretically, the bases of control and the sphere of political, social control and social work. It wonders about the possibility, in this society, of capital to maintain the control of the material base (social production) in order to ensure accumulation, and work to build control forms (social strategies) to address social inequalities and promote reversal of the capital's historical development of capitalism in their best interest. It argues that this articulation is problematic because of the capital determinations as well as the occurrence of cyclical and structural crises that, on the order hand, exacerbates and complicates the social consequences of the labor and social reproduction nowadays. It debates some historical strategies of coping with work on the structural determinations of capitalist control, discussing the limits of the relationship between the sphere of economy and politics.

\section{KEYWORDS}

Capitalism and social control. Social control and social work. Social policy and social control.

Submetido em 04/03/2011

Aceito em 30/04/2011

\section{INTRODUÇÃO}

Considerando a importância que o tema controle social assumiu para os assistentes sociais no debate sobre a gestão das políticas 


\section{temporalis}

SOUZA, R. M. de. POLÊMICAS E ESTRATÉGIAS CONTEMPORÂNEAS

sociais, no processo de redemocratização da sociedade brasileira, e ainda representa nos dias atuais, é que propomos, neste artigo, debater alguns elementos sobre a temática controle social. Referenciada na concepção marxiana, abordamos teoricamente as bases do controle na sociedade capitalista, a relação entre controle social e a esfera da política e, por último, algumas considerações sobre controle social e Serviço Social. Procuramos refletir se é possível nessa sociedade o capital manter o controle da base material (produção social) para garantir a acumulação, e o trabalho construir formas de controle (estratégias sociais) para enfrentar as desigualdades sociais e promover a reversão do desenvolvimento histórico do capitalismo a favor de seus interesses. Essa articulação é problemática devido às determinações do capital e à ocorrência das crises cíclicas e da crise estrutural que agrava e complexifica as conseqüências sociais da reprodução material e social do trabalho no mundo contemporâneo. Assim, problematizamos algumas estratégias históricas de enfrentamento do trabalho sobre as determinações estruturais do controle capitalista, discutindo os limites dessa relação entre a esfera da economia e a da política.

\section{BASES DO CONTROLE SOCIAL NA SOCIEDADE CAPITALISTA}

Entendemos que o controle social atinge as esferas da produção e da reprodução social. Desde as origens da humanidade o homem, através do trabalho, precisou exercer o controle sobre a natureza e transformá-la conforme suas necessidades materiais e sociais. Para Marx (1988a, p. 142), “[...] antes de tudo, o trabalho é um processo entre o homem e a Natureza, um processo em que o homem, por sua própria ação, medeia, regula e controla seu metabolismo com a Natureza". Essa mediação é, portanto, a base sobre a qual se constitui a sociedade e que, prevalecerá como atividade fundante nas diversas formações sócio-históricas. Deduz-se com isso que o controle da produção material, nas origens da sociedade, ou

Temporalis, Brasilia (DF), ano 10, n.20, p.49-76, jul./dez. 2010. 


\section{temporalis}

SOUZA, R. M. de. POLÊMICAS E ESTRATÉGIAS CONTEMPORÂNEAS

melhor, na comunidade primitiva, estava sob o domínio do trabalho, o que não será identificado nas sociedades que a sucederam.

No entanto, com a formação das sociedades de classes, como o escravismo e o feudalismo, o homem constituiu novas bases de organização social e de exploração do trabalho em que se evidenciavam a divisão social do trabalho, a propriedade privada e a produção do excedente econômico. Contudo, nessas sociedades, devido ao precário desenvolvimento das forças produtivas, baseado na agricultura e na pecuária, a condição de subordinação dos escravos e servos impedia a ampliação da produtividade e, por não ter se constituído uma classe revolucionária, o controle sobre a produção da riqueza foi completamente transformado. 0 feudalismo, em sua fase de transição e decadência, propiciou as condições para a gênese de uma nova sociedade, a sociedade capitalista, momento na história da humanidade em que se pôde expandir a produção da riqueza social, consolidando a submissão do interesse coletivo (trabalho) ao interesse privado de uma classe. Há, nesse sentido, uma inversão na reprodução material e social, ocorrendo a apropriação privada por uma classe (burguesia) do que é produzido coletivamente pelo trabalho.

É no capitalismo que o controle adquire uma particularidade em relação às demais sociedades, pois o capital assume a função determinante de controle social. O controle do capital sobre o trabalho incorpora esta dimensão social, e só pôde se desenvolver na sociedade quando conseguiu submeter o trabalhador à condição de assalariado, quando este se defrontou no mercado como vendedor de sua força de trabalho como algo independente de si próprio, como algo estranho, alheio. Ou seja, como mero produtor de valor. Daí advém a explicação de Marx de que o trabalho vivo é o único produtor da riqueza social e que o capital, a partir da extração 


\section{temporalis}

SOUZA, R. M. de. POLÊMICAS E ESTRATÉGIAS CONTEMPORÂNEAS

da mais-valia do trabalhador, sob circunstâncias históricas dadas, passa a deter o controle social sobre a produção da riqueza e do trabalho, inclusive sob a mistificação de que é o efetivo produtor desta. O capital, portanto, assume a função de controle das relações sociais e não pode prescindir do trabalho vivo enquanto substância da expansão de seu processo sociometabólico (MESZÁROS, 2002). Esta é, portanto, uma relação eminentemente social e determinante que constitui a esfera da economia, da reprodução da base material. O capital é produto de uma relação social - essa afirmação de Marx está comprovada na história da sociedade, e iremos destacar os elementos que a constituem.

No desenvolvimento da base material capitalista, o capital intervém para assegurar o controle da reprodução dos seus ciclos em movimento, tendo em vista garantir a produção, intensificar a acumulação e controlar as crises resultantes dessa dinâmica. Na esfera da política o controle social se expressa para regular a relação entre indivíduo e sociedade, ou seja, a relação entre as classes. Nessa esfera, o Estado $^{2}$ mantém uma relação de complementaridade com a economia, com a base material, e exerce o controle sobre a sociedade, em particular, sobre o trabalho, para dirimir os efeitos das desigualdades sociais desemprego, miséria, precariedade das formas de trabalho e das condições de vida, fome -, em face do agravamento da questão social no capitalismo dos monopólios e visando evitar os conflitos sociais entre as classes. No que se refere àquela relação de complementaridade, o Estado interfere na dinâmica da economia tanto na fase reguladora do capitalismo em que prevalece uma

\footnotetext{
${ }^{2}$ Isso quer dizer que "[...] não se pode pensar num Estado desembaraçado de seu papel vital. O Estado e o capital são totalmente inconcebíveis em separado. O Estado moderno surge como um complemento às estruturas econômicas do sistema do capital" (PANIAGO, 2001, p. 121).
} 


\section{tempordilis}

SOUZA, R. M. de. POLÊMICAS E ESTRATÉGIAS CONTEMPORÂNEAS

política keynesiana, quando como restringe sua intervenção econômica e reduz direitos e benefícios sociais aos cidadãos, no momento em que predominam alternativas de desenvolvimento baseadas no neoliberalismo. Com isso, afirmamos que a natureza do Estado é essencialmente liberal, e sua função social se constitui para reproduzir a desigualdade entre as classes, pois é um complemento para a manutenção das determinações econômicas do capital, o que significa que representa os interesses reprodutivos de uma dada classe. O reconhecimento da determinação histórico-social do Estado no capitalismo não engessa a dinâmica que ele assume na sociedade; sua forma se altera a depender da dinâmica sociometabólica do capital, mas sua natureza e função social, não. Há, portanto, uma relação intrínseca entre a esfera da economia e a da política, o que não iguala suas distinções fundamentais. A apreensão desses elementos se faz necessária para entender por que o controle social é eminentemente controle do capital sobre $\mathrm{O}$ trabalho. Retomaremos essa discussão adiante.

Na obra de Marx (1978), a temática controle explicita-se nas concepções de subsunção formal e de subsunção real do trabalho ao capital. Disso decorre a apreensão do controle como inerente à produção capitalista ${ }^{3}$ e como se renova a subordinação do trabalho ao capital para intensificar a extração do trabalho excedente. 0 controle atinge os processos de trabalho e as condições objetivas e

\footnotetext{
${ }^{3}$ A forma específica da produção capitalista se materializa na forma planejada de realizar trabalho cooperado, que produz, ao mesmo tempo, mudanças objetivas - aumento do número de mercadorias, diminuição do trabalho socialmente necessário, autonomização das condições de trabalho em relação ao trabalhador, economia no uso dos meios de trabalho, decorrente do consumo coletivo de muitos trabalhadores e mudanças subjetivas - como o reconhecimento da capacidade coletiva pelo trabalhador e, simultaneamente, o fenômeno de alienação do trabalho.
} 


\section{temporalis}

SOUZA, R. M. de. POLÊMICAS E ESTRATÉGIAS CONTEMPORÂNEAS

subjetivas de reprodução do trabalho, manifestando-se em formas coercitivas. Ele incide sobre objetos específicos e implica formas de disciplinamento da força de trabalho, de fragmentação do saber operário, de desqualificação profissional e de alienação do trabalho, marcando então a natureza da produção capitalista. O controle é tratado nas obras de Marx, de Gramsci e, contemporaneamente, no pensamento de Braverman, de Burawoy, de Senett, que expõem as formas de controle do capital em momentos históricos distintos.

A subsunção formal ${ }^{4}$ expressa o movimento de subordinação parcial do trabalho ao controle do capital. Nele, o trabalhador ainda detém domínio técnico e subjetivo sobre o processo de trabalho, o qual se expressa na habilidade artesanal e no controle dos instrumentos, sendo peculiar ao processo manufatureiro. No movimento de subsunção real o trabalhador perde o domínio sobre o produto e o processo de produção, devido ao rompimento das barreiras técnicas e subjetivas que impedem a expansão do capital de forma generalizada. O trabalho subsume-se integralmente às exigências da produção da mais-valia como um fim em si mesmo - mais-valia relativa. O trabalhador é utilizado como integrante de um organismo ativo que aumenta a sua capacidade produtiva pelo caráter coletivo e coordenado do trabalho generalizado com o processo de industrialização. 0 controle torna-se imanente à produção desde a manufatura, a grande indústria, até as formas históricas da produção capitalista contemporâneas do taylorismo-fordismo e da produção flexível.

\footnotetext{
4 Para Marx (1978, p. 54), “[...] o caráter distintivo da subsunção formal do trabalho ao capital se destaca, com maior clareza, mediante comparação com situações nas quais o capital já existe desempenhando determinadas funções subordinadas, mas não ainda em sua função dominante, determinante da forma social geral, em sua condição de comprador direto de trabalho e apropriador direto do processo de produção".
} 


\section{temporalis}

SOUZA, R. M. de. POLÊMICAS E ESTRATÉGIAS CONTEMPORÂNEAS

As formas de controle referem-se, portanto, às condições reais de organizar a produção capitalista e as relações sociais. Para Marx (1978), o capital ignora as necessidades básicas do trabalho a partir de uma relação de subordinação em que se dessubstancializa a unidade que compõe o processo produtivo na divisão do trabalho. O controle tanto remete às expressões objetivas quanto subjetivas de domínio do capital sobre o trabalho. No entanto, distingue-se das formas de controle subjetivas que se traduziram no domínio religioso ${ }^{5}$ e nas formas de servidão das sociedades precedentes vassalagem, formas patriarcais, escravidão -, sem o traço material característico das formas de controle capitalista. O controle se origina da exploração da força de trabalho, "[...] que o capital possui por natureza como sua força produtiva imanente" (MARX, 1988a, p. 251).

Marx (1988a) destaca na primeira forma capitalista de produzir cooperação e manufatura - que a função controle nasce no momento em que a atividade produtiva está concentrada num único comando. Na manufatura objetivam-se formas de controle que elevam a continuidade do trabalho, desenvolvem as variações da capacidade de trabalho e a relação entre proprietário dos meios de produção e trabalhador a uma mera relação monetária. Alterase a relação de superioridade e subordinação que, de traço servil, patriarcal, se tornou de natureza material, econômica e, ao mesmo tempo, livre e voluntária ${ }^{6}$, dada a venda da força de trabalho como

${ }^{5}$ O domínio religioso manifesta uma relação de controle subjetivo exercida pelos
representantes do poder político e religioso nas formas primitivas de
organização da sociedade capitalista, que fixa regras de convívio social e
religioso baseadas na superioridade sobre homens que ainda não desempenham
a função de livres vendedores da sua força de trabalho.
6 Embora o trabalhador se torne livre e venda voluntariamente sua força de
trabalho como mercadoria através de um contrato social que regulariza a
jornada de trabalho, depende desta venda para se reproduzir física e 


\section{temporalis}

SOUZA, R. M. de. POLÊMICAS E ESTRATÉGIAS CONTEMPORÂNEAS

mercadoria ao capital. Constituem-se a alienação do trabalho e o controle coercitivo. Ocorrem alterações no processo produtivo que traduzem as primeiras modificações da divisão do trabalho separação entre trabalhadores e propriedade das condições de realização do trabalho -, na adaptação dos instrumentos às funções específicas dos trabalhadores parciais, na habilidade artesanal mantida pela virtuosidade do trabalhador, no reduzido investimento em aprendizagem, na emergência dos supervisores na produção, na disciplina e hierarquia do trabalho posta pelo planejamento autoritário da produção e na exploração extensiva da força de trabalho pelo aumento da jornada de trabalho - maisvalia absoluta.

$\mathrm{Na}$ grande indústria, o capital torna-se a forma genérica de organização da produção social. Marx (1988b) postula que há continuidade de determinados aspectos do controle presentes na manufatura, contudo rompem-se as barreiras técnicas e subjetivas que impediam a expansão do capital. Ocorre a subsunção real do trabalho ao capital, o trabalho fica submetido inteiramente às exigências da produção de mais-valia relativa. O controle objetiva-se pela transformação da condição técnica do trabalho; o trabalhador torna-se um objeto de extração de mais-trabalho através do uso intensivo de maquinaria pela redução da jornada de trabalho. A introdução da maquinaria como instrumento de trabalho permite a diminuição dos poros da produção, o barateamento das mercadorias e a utilização do trabalho feminino e infantil, com extração de maisvalia relativa. Esse é o fundamento que explica a radical transformação no modo capitalista de produção no final do século

espiritualmente na sociedade. Só encontrará trabalho para exercer seu ofício ao vendê-lo no mercado. Essa é a contradição básica em que opera a sociedade capitalista - liberdade do trabalhador para produzir a riqueza material e para ser explorado.

Temporalis, Brasilia (DF), ano 10, n.20, p.49-76, jul./dez. 2010. 


\section{temporolis}

SOUZA, R. M. de. POLÊMICAS E ESTRATÉGIAS CONTEMPORÂNEAS

XVIII. A maquinaria ${ }^{7}$ constitui o órgão que centraliza a realização do trabalho coletivo combinado, diferentemente do princípio subjetivo da divisão do trabalho na manufatura. Ou seja, "[...] a partir do momento em que a máquina executa todos os movimentos necessários ao processamento da matéria-prima sem ajuda humana, temos um sistema de maquinaria automática capaz de ser continuamente aperfeiçoado em todos os seus detalhes" (MARX,1988b, p. 12). A produção mecanizada teve de revolucionar a base natural encontrada - o artesanato - por uma motivação consciente do capital.

Gorz (1996, p. 81), embora criticado por posições que validam a ideia do fim da sociedade do trabalho em outras obras, acrescenta ao debate sobre o caráter coercitivo do controle na fábrica, quando afirma que “[...] o despotismo na fábrica é tão velho quanto o próprio capitalismo [...]. O processo de produção deve ser organizado [e percebido] como uma exigência inerte da própria máquina, como um imperativo intrínseco à matéria". Essa afirmação de que a natureza da produção capitalista é despótica demonstra que são impostos ao trabalho a organização, os objetivos e as modalidades do trabalho fabril e que para se atingir os rendimentos que a produção capitalista exige - produção da mais-valia relativa - se torna necessário ocultar para o trabalhador que a exigência máxima da produção é algo imperativo à máquina e estranho ao trabalho. Tal imposição parece algo neutro e

7 Convém enfatizar que a "[...] criação da máquina é a resposta concreta, a versão mais bem elaborada e o maior testemunho para o fato de que o trabalho organizado em padrões manuais já não mais satisfazia às exigências do mercado. O capital recorreu, então, à ciência e à técnica; incorporou as descobertas e os avanços da mecânica, como mais tarde da eletricidade, da eletrônica; transformou o trabalho do cientista em sua mais importante força produtiva, dissolvendo os últimos vestígios dos elementos naturais. Nascia a ciência aplicada e a Revolução Industrial” (MELLO, 1999, p. 91). 


\section{temporalis}

SOUZA, R. M. de. POLÊMICAS E ESTRATÉGIAS CONTEMPORÂNEAS

inerente ao processo, e o trabalhador deve adequar-se a tal condição de modo que seja inviabilizado qualquer movimento de contestação. Para atingir o objetivo da acumulação capitalista, a finalidade da produção deve se contrapor à satisfação, à necessidade, ao valor de uso das mercadorias em favor do trabalho. Segundo os argumentos apresentados por Gorz (1996), entendemos que a história do capitalismo industrial só pode ser compreendida como a história do capital pela via despótica de controle da força de trabalho. A razão da coerção, segundo ele, deve ser buscada na divisão do trabalho, na medida em que os objetivos do capital devem permanecer estranhos aos do trabalho. Conforme os pressupostos marxianos, o controle se desenvolve para tornar os meios - instrumentos, máquinas - e o processo de produção como elementos estranhos ao trabalho, o que exige uma maior subordinação.

Nas formas de controle contemporâneas no taylorismo-fordismo e na produção flexível também são identificadas as bases coercitivas do controle, pois a natureza capitalista foi apenas aperfeiçoada em face das alterações tecnológicas e dos processos de acumulação, dadas as crises capitalistas de natureza cíclica e estrutural. Com o taylorismo-fordismo são operacionalizadas inúmeras mudanças que darão um contorno diferenciado à expansão capitalista no século XX. Aperfeiçoando a Teoria da Administração Cientifica de Taylor - separação entre concepção, controle e execução -, Ford consolida a disciplina, a hierarquia das funções e a rigidez da produção, inovando em termos de produção em massa. Sua peculiaridade é que penetrou na sociedade como um novo sistema de reprodução da força de trabalho que, além de permitir uma renda satisfatória para o consumo dos produtos, ampliou o controle sobre a vida do indivíduo, em geral, às questões familiares, da sexualidade, da probidade moral, ou seja, um novo padrão de conduta do trabalhador. Essa é uma forma diferenciada

Temporalis, Brasilia (DF), ano 10, n.20, p.49-76, jul./dez. 2010. 


\section{tempordilis}

SOUZA, R. M. de. POLÊMICAS E ESTRATÉGIAS CONTEMPORÂNEAS

de controle social dos processos iniciais da produção capitalista, embora mantenha a essência da articulação entre produção e reprodução social.

Em face da incapacidade das forças econômico-sociais de controlar através do fordismo e das políticas keynesianas as contradições inerentes ao desenvolvimento capitalista nos anos de 1970, ensaiase a transição da rigidez fordista para a era da acumulação flexível. Instaura-se o modelo toyotista de base flexível, que introduz novos meios de trabalho (flexibilidade das linhas de produção) e os conhecimentos inovadores da informática e da microeletrônica, adequando-os à instabilidade dos mercados. Diferentemente do fordismo, traduz uma série de técnicas organizacionais e de relações de trabalho em face do mercado restrito para atender à demanda. Sob uma suposta autonomia do processo de trabalho este modelo toyotista exige um controle mais intenso da força de trabalho, pela "[...] necessidade de implantar formas de capital e de trabalho intensivo" (ANTUNES, 1999, p. 55-56). As mudanças na gestão do controle são evidentes, no entanto, mantém-se sua dimensão econômica, que não só sustenta a reprodução do capital, como inova em termos de sua tendência de expansão.

\section{CONTROLE SOCIAL E ESFERA DA POLÍTICA}

Para Mészáros (1987, p. 32), “[...] no decurso do desenvolvimento humano, a função de controle social foi alienada do corpo social e transferida para o capital, que adquiriu assim o poder de aglutinar os indivíduos num padrão hierárquico estrutural e funcional". Contudo, esse autor destaca que no mundo contemporâneo, com a crise estrutural, as contradições do capitalismo tornam-se cada vez mais explosivas, demonstrando o caráter irracional do controle social. Em suas palavras, "[...] a crise que enfrentamos não se reduz simplesmente a uma crise política, mas trata-se da crise 


\section{temporalis}

SOUZA, R. M. de. POLÊMICAS E ESTRATÉGIAS CONTEMPORÂNEAS

estrutural geral das instituições capitalistas de controle social na sua totalidade" (MÉSZÁROS, 1987, p. 53).

As contradições do capitalismo atual se manifestam nos índices de pauperização, no desemprego crônico, na intensificação da taxa de exploração do trabalho, na devastação do meio ambiente, na amplitude da violência nas diversas esferas (urbana, trabalho etc.), nas formas de alienação, na desestruturação de relações sociais que configuram o status quo dominante. Com essas consequências sociais explicita-se "[...] a contradição [fundamental] entre uma perda efetiva de controle e a forma vigente de controle, o capital, que pela sua própria natureza somente pode ser controle dado que é constituído mediante uma objetificação alienada da função de controle, como um corpo reificado separado e em oposição ao próprio corpo social” (MÉSZÁROS, 1987, p. 33). A irracionalidade do controle demonstra o limite da expansão do capital sobre a sociedade, pois "[...] os limites do capital colidem com os limites da própria existência humana” (MÉSZÁROS, 1987, p. 37). O capital, ainda que de forma reificada, está sendo compelido a tomar conhecimento de seus próprios limites. Em face dessa complexidade histórica do momento, para o autor não causa espanto o surgimento e a disseminação da ideia do controle pelos trabalhadores nesta sociedade. Embora importantes reações dos trabalhadores venham ocorrendo, entendemos que se constituem num controle restrito, pois atingem aspectos da reprodução da força de trabalho e não o cerne do sistema do capital que funda a existência da questão social.

Ao tratarmos dos aspectos referentes à reprodução capitalista no item anterior, parece que a base material, econômica, técnica da produção fosse desprovida de dimensão política e social. Os elementos determinantes da produção social revelam o quanto foi e é necessário para o capital exercer o controle social sobre o 


\section{tempordils}

SOUZA, R. M. de. POLÊMICAS E ESTRATÉGIAS CONTEMPORÂNEAS

trabalhador, para que a natureza alheia (alienada) do trabalho pudesse e possa ser assimilada como única pelo operariado e pela sociedade em geral. Marx $\left(1978,1988^{a}, 1988 b\right)$ se refere a essas formas de controle como controle social tanto em termos da produção quanto da reprodução social. Ao explicitar a subsunção formal e real, está tratando da forma social da produção capitalista e desta determinação sobre a vida dos indivíduos. Para ele só seria possível pensar no controle social do trabalho na sociedade, em termos reais e plenos nas esferas da economia e da política, quando se concretizasse a superação da ordem capitalista.

Sem eliminar o capital e suas bases estruturantes não há possibilidade de domínio do trabalho sobre a produção social da sociedade, e tampouco na esfera da política, principalmente pela subordinação dessa esfera à base material. A política é meio, não é fim. Longe de expressar um conjunto de medidas estratégicas que afetem profundamente a estrutura dessa sociedade, a política corresponde a um conjunto de ações esporádicas, desprovidas de uma finalidade explícita. Conforme salienta Mészáros, (1987, p. 53): "A política fica condenada a seguir um padrão de movimento reativo tardio e de curto prazo, em resposta às crises desconcertantes que irrompem, numa frequência crescente, na base econômico-social [...] da acumulação de capital".

Sobre os limites da intermediação política do Estado em relação ao trabalho, Paniago (2009, p. 8) destaca que

Os trabalhadores perderam, e continuam a perder; o capital conseguiu se impor sem uma oposição política equivalente à gravidade das medidas opressivas contra o trabalho, na base material da produção, amparadas pelo autoritarismo das mediações políticas e de seu Estado. Reafirmou-se o fundamento da própria produção capitalista - 'capitalistas de um 


\section{temporalis}

SOUZA, R. M. de. POLÊMICAS E ESTRATÉGIAS CONTEMPORÂNEAS

lado, assalariados de outro' -, uma relação em que o trabalho se encontra subordinado ao capital, não podendo livrar-se dele enquanto permanecer vigente o quadro estrutural da produção de mercadorias. Essas determinações causais definem o espaço para as reivindicações e conquistas dos trabalhadores, mas sempre no sentido de preservar a relação de dependência (capital e trabalho abstrato), jamais no sentido da eliminação da relação de exploração. Os imperativos da produção de valor extraído da força de trabalho é que definem o objeto e a margem da distribuição da riqueza, e não o contrário. No momento em que a acumulação de capital necessitou recompor sua taxa de lucratividade, como imposição da crise estrutural, nada impediu a ofensiva do capital sobre o trabalho, impondo-lhe a retirada dos ganhos anteriormente concedidos.

O Welfare State, enquanto exemplo histórico de Estado, representou ganhos materiais e legais (acesso às políticas sociais de caráter universal e de direitos trabalhistas) para a classe média trabalhadora, promovendo-a principalmente à condição de consumidora em massa dos produtos fordistas. A política keynesiana regulatória correspondeu às alternativas necessárias para a saída da crise dos anos 20 e 30 no mundo capitalista. No entanto, "[...] a força dos trabalhadores ao 'arrancar' do capital melhores condições de vida e de trabalho colaborou para a revitalização do sistema como um todo, transformando uma aparente vitória do trabalho diante do capital em fortalecimento de seu domínio e êxito" (PANIAGO, 2009, p. 3). Eis uma ironia histórica ao trabalho: seria possível através do acirramento da luta democrática pelo controle social alcançar-se a emancipação do trabalho? Produz-se a ilusão de que é possível reduzir a exploração do trabalho, colocar limites ao capital, sem alterar a base de seu sistema.

O que foi vivenciado pelos países centrais na era do Welfare State, não desconsiderando certa melhoria nas condições de reprodução social do trabalho (cidadania - direitos sociais e trabalhistas), não 


\section{tempordilis}

SOUZA, R. M. de. POLÊMICAS E ESTRATÉGIAS CONTEMPORÂNEAS

significou nenhuma superação nem ampliação efetiva do controle do trabalho sobre a reprodução social. Representou efetivamente um período expansionista do capital, que retardou durante 30 anos o colapso de seu sistema e a confirmação dos limites de suas ações remediadoras para controlar as crises. No Welfare State foram atingidos os efeitos, as consequências da reprodução capitalista, pois nos anos de 1970 demonstra-se objetivamente no mundo o acirramento das suas contradições basilares.

De modo peculiar, Marshall (1967) em sua obra Cidadania, classe social e status, ao tratar da cidadania na sociedade contemporânea, fundamenta-se no suposto de que existem classes sociais antagônicas e que a luta pela conquista dos direitos é mediada pelo Estado. Acrescenta que a cidadania não é incompatível com as desigualdades econômicas e sociais. A cidadania não implica, para ele, superação das desigualdades no capitalismo, mas a redução dos seus níveis mais elevados através de uma estratégia governamental de suposta distribuição da riqueza. A intenção não é superar ou erradicar as desigualdades, apenas amenizá-las, possibilitando o acesso de parcela da classe trabalhadora ao emprego, aos benefícios sociais e aos direitos trabalhistas. Esta é a expressão mais moderna de sujeitos de direitos e deveres, que constituem a base da cidadania ${ }^{8}$.

8 Para enriquecer o debate, destacamos a crítica de Tonet (2001) à cidadania: "Considerados apenas neste aspecto de membros da sociedade civil, todos os homens são livres, iguais e proprietários. Mas o que significa exatamente isto? $\mathrm{O}$ que significa a liberdade para este homem 'natural'? Significa o 'direito' de buscar, por todos os meios ao seu alcance, a satisfação dos seus interesses, o que implica necessariamente o choque e a luta contra os indivíduos, movidos pela mesma lógica. Mesmo esta liberdade, porém, não passa de uma aparência de liberdade, dado que não é nem pode ser ele que decide, livre e conscientemente, sua forma de atividade, mas esta lhe é imposta pela natureza alienada das relações sociais. Por sua vez, a igualdade significa que todos os homens têm o mesmo 'direito' de mover-se de acordo com esta lógica. [...] 


\section{temporalis}

SOUZA, R. M. de. POLÊMICAS E ESTRATÉGIAS CONTEMPORÂNEAS

Isso nos mostra o quanto a conquista da cidadania, dos direitos sociais está plenamente adequada à convivência com as desigualdades econômicas e sociais. A história do capitalismo demonstra o quanto a efetividade das políticas sociais (padrão de proteção social ao trabalho) esteve restrita à experiência dos países centrais e que os países periféricos apenas ampliaram sua condição de subordinação econômica, com o aumento da pobreza e do desemprego, assumindo até mesmo feição estrutural, conforme atesta Mészáros (2002).

Chegamos, então, ao debate de um elemento muito caro ao Serviço Social: o entendimento sobre a esfera da política. A esfera da política é compreendida de forma diferenciada entre os próprios marxistas. No nosso entendimento, esta esfera formalizase historicamente quando o indivíduo passa a ser concebido como cidadão, membro da sociedade burguesa, cujos direitos de igualdade, liberdade, segurança e propriedade constituem os direitos humanos universais (MARX, 1991). O cidadão burguês é o indivíduo voltado aos seus interesses particulares, conforme os princípios liberais do capitalismo. Ele participa da esfera da política, submetendo o interesse particular ao interesse geral - vontade coletiva representada no Estado -, sem, entretanto, romper com o interesse individual burguês. A concepção liberal de cidadania,

Enfim, a propriedade significa que todos eles dispõem de algum bem que pode ser de interesse para os outros, enquanto cada um tem carências para cuja satisfação deverá entrar no circuito da troca mercantil” (TONET, 2001, p. 99). E prossegue: "A comunidade política, da qual o cidadão é o momento essencial, não é nem poderá ser uma comunidade real, efetiva, porque no solo social que Ihe dá origem as relações entre os homens não são de união, mas de oposição, não são de mútuo enriquecimento, mas de mútua desapropriação. $\mathrm{E}$, se alguma união existe entre eles, ou é como uma imposição jurídico-política, ou como uma reação alienada (solidariedade, assistência, 'campanhas de fraternidade') ou, ainda, como resistência e como luta, tendo em vista a construção de uma comunidade efetivamente humana" (TONET, 2001, p. 101). 


\section{temporolis}

SOUZA, R. M. de. POLÊMICAS E ESTRATÉGIAS CONTEMPORÂNEAS

herdeira do pensamento de Hobbes, Locke e Rousseau está assentada no pressuposto de que todos os homens são iguais e livres por natureza. A liberdade é, portanto, considerada um bem natural da sociedade.

Reafirmamos que a cidadania, constitutiva da esfera da política, não implica superação das contradições capitalistas expressas nas desigualdades sociais; ela reflete um estágio civilizado das relações humanas em que o homem ainda está submisso ao limite da emancipação política, da conquista dos direitos - liberdade política. A emancipação política "[...] não é o modo radical e isento de contradições da emancipação humana. O limite da emancipação política manifesta-se imediatamente no fato de que o Estado pode livrar-se de um limite sem que o homem dele se liberte realmente" (MARX, 1991, p. 23). A emancipação política promove a "[...] redução do homem, de um lado, a membro da sociedade burguesa, a indivíduo egoísta independente e, de outro, a cidadão do Estado, a pessoa moral" (MARX, 1991, p. 52).

O Estado enquanto instância reguladora dos conflitos sociais atua para consolidar a emancipação política, administrando as desigualdades sociais. A diferença para o pensamento marxiano é que a política não se constitui de forma autônoma na sociedade, pois está articulada à economia, à base material, não existe em separado da produção social. A esfera da política mantém também uma relação de dependência com a base econômica, e desta condição se explica seu limite e sua importância estratégica na sociedade. Apesar de ser nesta esfera que os conflitos sociais se expressam, é no modo de produção da existência material que as desigualdades sociais entre as classes se constituem, encontrandose aí os fundamentos dos males sociais. "O equívoco metodológico consiste, pois, em tomar a esfera da política, que é parte, momento da totalidade social, como princípio, como fundamento da 


\section{temporalis}

SOUZA, R. M. de. POLÊMICAS E ESTRATÉGIAS CONTEMPORÂNEAS

inteligibilidade dos fenômenos sociais" (TONET, 1995, p. 50). Como se o indivíduo arbitrariamente pudesse eleger na vida em sociedade qualquer elemento como princípio que fundamenta o todo. Segundo Tonet (1995, p.50), Marx atribui “[...] ao intelecto político a incapacidade de compreender as causas dos males sociais", isso porque seu princípio reside exatamente na onipotência da vontade, na prevalência da vontade política. "O intelecto político é político exatamente na medida em que pensa dentro dos limites da política" (MARX, 2009, p.11).

Na história da sociedade moderna, quando se atribuiu à política o campo de resolutividade da problemática social foram operadas diversas inversões. Atribuiu-se à ineficiência, à inoperância, à corrupção das ações administrativas e assistenciais do Estado e de seus administradores a responsabilidade pela não eliminação da pobreza e do desemprego. A solução seria produzir outra forma de Estado ou aperfeiçoá-lo, reformá-lo, para garantir o bem-estar de todos. Esta ação em nada altera as causas dos males sociais; apenas atua sobre suas consequências, pois nega 0 reconhecimento da classe burguesa como responsável pela existência desses males. Com isso, preserva-se a natureza do próprio Estado, que é regular as relações sociais, e não eliminar os fundamentos das desigualdades sociais - a gênese da relação capital $\mathrm{x}$ trabalho. Convém salientar que, apesar do cerne da contradição burguesa estar na esfera da economia, é na esfera da política que o acirramento dos conflitos sociais poderá chegar ao limite, produzindo momentos de ruptura com a sociedade capitalista. Este é o campo em que se movimenta a política para manter o controle social burguês.

De modo diferenciado, o controle social não matizado pela contradição capital $x$ trabalho só é possível através do controle integral do trabalho sobre sua vida noutra sociedade. O controle 


\section{temporolis}

SOUZA, R. M. de. POLÊMICAS E ESTRATÉGIAS CONTEMPORÂNEAS

social não é um conceito evidente, já que o controle do capital, embora privado, também é social. Se faz necessário precisá-lo. Por controle social do trabalho entendemos, na esteira de Marx, "[...] o domínio consciente e coletivo dos produtores sobre o conjunto do processo de produção, distribuição e consumo" (TONET, 2001, p. 115). Processo este em que a produção teria como objetivo atender às necessidades humanas em vez da reprodução do capital, o que demonstra sua confluência com a emancipação humana.

Entende-se, portanto, que é por meio da emancipação humana que

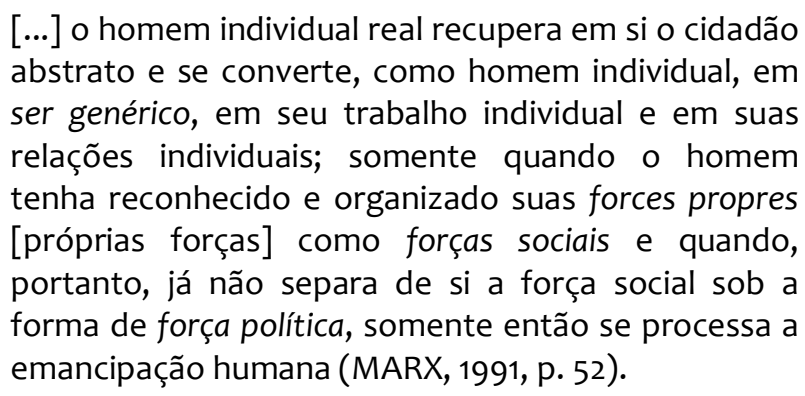

É no momento em que os homens podem se realizar plenamente como seres sociais e se libertar dessa contradição que ocorre a emancipação política: de um lado, indivíduo egoísta, e de outro, cidadão do Estado.

Para Mészáros (1987, p. 69-70), o controle social só pode ser definido em detalhes e exercitado na fase transitória do socialismo, pois dependem da sua articulação prática com as estratégias alternativas que têm domínio crítico dos elementos e determinam o controle social da sociedade em desintegração. Assim, ele se limita a mencionar os aspectos mais importantes - a relação entre economia e política: 


\section{temporalis}

SOUZA, R. M. de. POLÊMICAS E ESTRATÉGIAS CONTEMPORÂNEAS

Como se sabe, os críticos burgueses de Marx nunca deixaram de acusá-lo de usar de 'determinismo econômico'. Porém nada poderia estar mais distante da verdade. Isto porque o programa marxiano é formulado exatamente como a emancipação da ação humana do poder das implacáveis determinações econômicas. Quando Marx demonstrou que a força bruta do determinismo econômico, desencadeada pelas desumanizadoras necessidades da produção do capital, impera sobre todos os aspectos da vida humana, demonstrando ao mesmo tempo o caráter inerentemente histórico - ou seja, necessariamente transitório - do modo de produção predominante, ele tocou a ferida da ideologia burguesa: o vazio de sua crença metafísica na "lei natural" das relações de produção vigente. E, ao revelar as contradições inerentes a esse modo de produção, ele demonstrou a necessária ruptura de seu objetivo, o determinismo econômico. Tal ruptura, todavia, teve de se consumar pela extensão aos seus limites extremos, submetendo absolutamente tudo - incluindo a suposta autonomia do poder de deliberação política ao seu próprio mecanismo de controle estrito; ironicamente, porém, quando isso é alcançado (como resultado de crescente apetite por 'corretivos', concebidos para assegurar a ilimitada expansão do poder do capital), [...]. A completa e, agora, patente subordinação da política aos ditames mais imediatos do determinismo econômico da produção do capital é um aspecto vital dessa problemática. Esta é a razão por que o caminho para o estabelecimento de novas instituições de controle social deve passar através de uma radical emancipação da política do poder do capital (MÉSZÁROS, 1987, p. 69-70).

A ofensiva dos trabalhadores contra o capital para constituir a sociedade dos produtores associados depende do enfrentamento consciente do trabalho dos elementos constitutivos do controle 


\section{temporalis}

SOUZA, R. M. de. POLÊMICAS E ESTRATÉGIAS CONTEMPORÂNEAS

capitalista dominante: propriedade, formas de produção e acumulação capitalista, exploração intensa do trabalho, alienação e o Estado. O processo de construção do controle social requer o envolvimento ativo da comunidade dos produtores associados através da reativação das energias criativas reprimidas dos diversos grupos sociais e do cultivar da dimensão coletiva da organização social. Um processo global, radical, intenso e efetivamente coletivo, que supere as ações parciais de indivíduos e/ou grupos sociais. Momento em que seria possível articular a esfera da política à da economia. Segundo Marx (1995, p.90) uma "[...] revolução política com alma social [...]".

\section{CONTROLE SOCIAL E SERVIÇO SOCIAL}

Conforme exposto na introdução o debate sobre o controle social adquire relevância no Serviço Social com o processo de democratização da sociedade brasileira, após a ditadura militar. Destacamos também que a aproximação do Serviço Social ao marxismo desde os idos do Movimento de Reconceituação, e nos anos de 1980 com a recorrência às fontes originais marxianas, possibilitou entender as determinações histórico-sociais do capitalismo sobre a gênese e natureza da profissão na sociedade, o que contribuiu politicamente para a profissão entender e desvendar as desigualdades sociais resultantes da reprodução capitalista.

Neste contexto, ampliam-se as instâncias políticas de participação profissional na elaboração de planos, programas e projetos no âmbito das políticas sociais. $\mathrm{E}$ os assistentes sociais são requisitados para participar da gestão dos Conselhos, Conferências e Fóruns nas esferas estaduais e municipais, como mecanismos necessários para concretizar os processos de municipalização e descentralização das políticas sociais. Esses Conselhos e Conferências são considerados espaços de resistência da classe 


\section{temporalis}

SOUZA, R. M. de. POLÊMICAS E ESTRATÉGIAS CONTEMPORÂNEAS

trabalhadora às restrições dos direitos e gastos sociais que configuram as tendências atuais à focalização e à mercantilização das políticas sociais com o neoliberalismo. São, desse modo, instâncias governamentais em que se exercita o controle social sobre as políticas públicas, avaliando, fiscalizando e acompanhando as ações do Estado. Para Correia (2005, p. 224), controle social é "[...] o controle da sociedade sobre o destino das políticas sociais, para que atendam aos reais interesses da maioria da população". No entanto, a autora reconhece os limites e as contradições que envolvem as práticas de controle social, quando argumenta que à medida que podem aglutinar segmentos da classe trabalhadora no exercício da fiscalização das ações do Estado, podem, por outro lado, fortalecer o poder institucional e facilitar a criação de mecanismos de manipulação e de cooptação das lideranças dos movimentos sociais.

Entendemos o significado histórico das lutas sociais contra a ofensiva neoliberal no âmbito das políticas sociais na atualidade, entretanto ressaltamos os limites da intervenção dos profissionais e representantes da classe trabalhadora nesses espaços da gestão pública estatal. Os argumentos dos defensores do controle social na esfera da política tanto estão assentados nos aspectos políticos como nos aspectos econômicos - controle dos trabalhadores sobre o fundo público e sobre os processos de acumulação de capital e aspectos relacionados à reprodução da força de trabalho. Assim, esse fundo público tanto é utilizado para subsidiar a produção industrial e agrícola e os serviços de infraestrutura, como também financia a reprodução da força de trabalho, ou seja, quando o investimento é orientado para garantir bens e serviços de consumo coletivo, a exemplo saúde, educação, assistência, entre outros.

Temporalis, Brasilia (DF), ano 10, n.20, p.49-76, jul./dez. 2010. 


\section{tempordilis}

SOUZA, R. M. de. POLÊMICAS E ESTRATÉGIAS CONTEMPORÂNEAS

É inegável a contribuição política dos setores organizados da classe trabalhadora e dos assistentes sociais nessa gestão, no entanto, indagamos: por que as resultantes desta intervenção política nos Conselhos não alteram essencialmente as estratégias institucionais que incidem sobre as condições precárias de reprodução do trabalho?

Dentre os limites do controle social, Correia (2005, p. 227) aponta "[...] que os objetivos do controle social estão na contramão [dos interesses públicos coletivos] e parecem cada vez mais inatingíveis [...]", principalmente com o refluxo dos movimentos sociais na década de 1990. Pode-se afirmar que os Conselhos têm se constituído em espaços para garantir o repasse de recursos financeiros na gestão das organizações sociais, subsídios para a rede privada em detrimento da ampliação da rede pública.

A questão que indicamos não consiste em negar os mecanismos criados pelos segmentos da classe trabalhadora, mas em entender os limites do controle social numa sociedade essencialmente desigual, uma vez que promove apenas um controle restrito da sociedade civil sobre o desenvolvimento da sociedade. O Estado constitui-se para garantir a coesão social, o consenso entre as classes, em suma, para administrar os conflitos sociais, lidando com as contradições da sociedade que derivam da produção da existência material. Embora explicite a dinâmica contraditória do capitalismo, só existe para regular a contradição, jamais para superá-la. Seu limite está na sua essência, na sua natureza. Sua dinâmica reflete o conjunto das forças políticas presentes na sociedade. Num dado momento faz concessões à classe trabalhadora em função da necessidade de legitimidade social e da pressão da forças de resistência, no entanto, isso não nega sua essência - representar os interesses das classes dominantes. É o que move a dinâmica do Estado, ainda que os trabalhadores tenham construído historicamente formas de enfrentamento. 


\section{temporalis}

SOUZA, R. M. de. POLÊMICAS E ESTRATÉGIAS CONTEMPORÂNEAS

A base objetiva da lógica do sistema é que dá (ou retira) a sustentação das conquistas políticas do trabalho. Da mesma forma, este quadro de crise estrutural, e as necessidades reprodutivas do sistema como um todo é que definem a 'margem da ação transformadora' pela luta de classes. Se a ilusão democrática reformista prevaleceu num terreno favorável de crescimento do capital, as condições atuais da crise estrutural exigem uma reorientação da luta do trabalho por seus direitos. Mesmo as conquistas mais parciais só poderão ser realizadas numa luta contra o capital, pois não se trata de um cenário de restrições e austeridade de base conjuntural, ou passageira (PANIAGO, 2009, p. 5).

Os trabalhadores, de forma organizada, precisam enfrentar radicalmente os elementos centrais constitutivos do controle social do capital. Conforme Paniago (2009), a ilusão democrática da conquista de direitos na era da social-democracia produziu a falsa ideia de concessão do capital em favor do trabalho, contribuindo para um afastamento dos ideários de classe mais radicais que avançaram a partir da crise estrutural. Convém considerar, portanto, que o desemprego estrutural, as formas de trabalho precárias, o não acesso a bens, serviços e equipamentos de uso coletivo, a perda de direitos e o crescimento exponencial do pauperismo têm interferido decisivamente para limitar as ações coletivas dos trabalhadores que denunciam as suas condições precárias de reprodução social. Eis os limites reais com os quais o Serviço Social e os diversos segmentos organizados se deparam na sociedade atual.

\section{CONSIDERAÇÕES FINAIS}

Entendemos que o controle da produção material e da vida dos indivíduos sobre o domínio consciente e livre do trabalho como 


\section{tempordilis}

SOUZA, R. M. de. POLÊMICAS E ESTRATÉGIAS CONTEMPORÂNEAS

controle social está para além da sociedade do capital (MÉSZÁROS, 2002). Segundo Marx (1988b, p. 153), “[...] o capital pressupõe o trabalho assalariado, o trabalho assalariado o capital. Condicionamse reciprocamente e se criam reciprocamente [...]". Para realizar o controle social o homem enquanto ser social teria de superar essa condição, que o aliena e o impede de alcançar a emancipação humana. O controle social supõe, portanto, o domínio consciente do trabalho sobre a reprodução social da vida humana. Ele requer a efetiva emancipação humana e a superação do controle do capital. Essa é a única possibilidade de o trabalho enfrentar o domínio do capital. As formas atuais de controle social, embora respeitando os projetos políticos avançados da classe trabalhadora e as lutas de resistência, na sua maioria apenas amenizam os efeitos desastrosos do capital sobre a reprodução do trabalho, exercendo uma funcionalidade efetiva à reprodução capitalista. É preciso, portanto, entender os fundamentos que explicam o controle social, a dinâmica do capital e a relação de subordinação do trabalho. O controle social pelo trabalho supõe, portanto, a efetividade de seu projeto revolucionário através do fortalecimento das lutas sociais que enfrentem os determinantes estruturais do capital.

Apresentamos algumas questões polêmicas sobre o tema controle social. Não pretendemos com isso esgotar a discussão, mas tão somente problematizar elementos que consideramos fundamentais para o debate teórico no Serviço Social.

\section{REFERÊNCIAS}

ANTUNES, Ricardo. Os sentidos do trabalho: ensaio sobre a afirmação e a negação do trabalho. São Paulo: Boitempo,1999. 


\section{temporalis}

SOUZA, R. M. de. POLÊMICAS E ESTRATÉGIAS CONTEMPORÂNEAS

CORREIA, Maria V. C. O controle social das políticas públicas: limites e desafios para o serviço social. In: CORREIA, Maria V. C. (Org.). Desafios para o controle social: subsídios para as capacitações de conselheiros de saúde. Rio de Janeiro: Ed. Fundação Oswaldo Cruz, 2005. v. 1, p.221-231.

GORZ, André. O despotismo da fábrica e suas consequências. In: GORZ, A. (Org.). Crítica da Divisão do Trabalho. São Paulo: Martins Fontes, 1996. p.79-89.

MELLO, Alex F. Marx e a globalização. São Paulo: Boitempo, 1999.

MARSHALL, T. Cidadania, classe social e status. Rio de Janeiro: Zahar, 1967.

MARX, Karl. Resultados do processo imediato de produção. In:

Capítulo VI Inédito. São Paulo: Livraria Editora Ciências Humanas, 1978.

.o Capital: v. 1. tomo 1. São Paulo: Nova Cultural, 1988a. (Coleção Os Economistas).

. O Capital: v. 1. tomo 2. São Paulo: Nova Cultural, 1988b. (Coleção Os Economistas).

. A questão judaica. São Paulo: Editora Moraes, 1991.

- Glosas críticas marginais ao artigo O rei da Prússia e a reforma social. De um prussiano. Práxis, Belo Horizonte, n. 5, p. 68-91, 1995.

MÉSZÁROS, István. A necessidade do controle social. São Paulo, Editora Ensaio, 1987 (Cadernos Ensaio, Pequeno Formato). 


\section{tempordilis}

SOUZA, R. M. de. POLÊMICAS E ESTRATÉGIAS CONTEMPORÂNEAS

. A produção da riqueza e a riqueza da produção. In: . Para

além do capital: rumo a uma teoria da transição. São Paulo: Boitempo; Campinas-SP: Ed. Unicamp, 2002. Cap. 14, p. 605-629.

PANIAGO, Maria C. S. A incontrolabilidade ontológica do capital: um estudo sobre Beyond Capital, de I. Mészáros. 2001. Tese (doutorado em Serviço Social) - Universidade Federal do Riode Janeiro (UFRJ/ ESS), Rio de Janeiro.

- A Crise Estrutural do Capital, os Trabalhadores e o Serviço Social. In: SEMINARIO LATINOAMERICANO DE ESCUELAS DE TRABAJO SOCIAL, 19., 2009. Anais... Guayaquil-Ecuador: ALAEITS, 2009. p. 1-13 (Slets: 019-178).

TONET, Ivo. Educação, cidadania e emancipação humana. 2001. Tese (doutorado) - Universidade Estadual Paulista, São Paulo.

- Marx e a política: prefácio ao Glosas críticas... de Marx. In: Práxis, Belo Horizonte, n. 5. p. 45-68, 1995. 